\title{
Solarização do solo e biofumigação no cultivo protegido de tomate
}

\author{
Mírian Josefina Baptistaㄹ ${ }^{1}$ Ronessa B de Souza' ${ }^{1}$, Welington Pereira ${ }^{1}$; Osmar A Carrijo ${ }^{1}$; Mariane C \\ Vidal $^{1}$; João Maria Charchar ${ }^{1}$ \\ ${ }^{1}$ Embrapa Hortaliças, C. Postal 218, 70359-970 Brasília-DF. E-mail: mirian@cnph.embrapa.br
}

\begin{abstract}
RESUMO
Foi avaliado o efeito da fumigação com brometo de metila, biofumigação e da solarização sobre a população do fitonematóide Meloidogyne sp., a incidência de plantas daninhas e características químicas do solo em ambiente protegido para o plantio de tomate. Foram testados os tratamentos: resíduos de couve-flor e de brócolos $(2 \% \mathrm{v} / \mathrm{v})$, cama de aves $(2 \% \mathrm{v} / \mathrm{v})$, fumigação com brometo de metila e solo não tratado, todos com e sem solarização. $\mathrm{O}$ período de solarização foi de dois meses e, em seguida, foi feito o plantio dos híbridos de tomate Alambra, resistente a Meloidogyne incognita (gene Mi), e Duradoro (suscetível). O banco de sementes de plantas daninhas no solo foi avaliado em amostras retiradas do perfil de 0 a 20 $\mathrm{cm}$ de profundidade, com amostragem das plantas daninhas emergidas aos 30 dias após o transplante do tomate. Para as análises químicas foram retiradas amostras de solo após a solarização e biofumigação. A solarização do solo, uso de cama de aves e fumigação com brometo de metila reduziram a população de nematóides no solo e o número de massas de ovos nas raízes dos dois híbridos avaliados. O híbrido Alambra, no entanto, apresentou massa seca e fresca da parte aérea, altura e peso de frutos, na primeira colheita, maiores nos solos solarizados, respondendo melhor à solarização que o 'Duradoro'. A fumigação com brometo de metila e a solarização reduziram a viabilidade das sementes e a sobrevivência de plantas daninhas. A solarização aumentou os teores de fósforo e de cobre e reduziu os teores de zinco no solo.
\end{abstract}

Palavras-chave: Lycopersicon esculentum, Meloidogyne sp., desinfestação do solo, controle físico, plantas daninhas, matéria orgânica.

\begin{abstract}
The effect of solarization and biofumigation on tomatoes under protected cultivation

A greenhouse experiment was carried out to test the effects of solarization and biofumigation on the population of the plant parasitic nematode Meloidogyne sp., on the incidence of weeds and on soil chemical properties in protected areas for the cultivation of tomatoes. Brassica residues (broccoli and cauliflower) and chicken litter amendments $(2 \% \mathrm{v} / \mathrm{v})$, methyl bromide and no amendment were evaluated with or without solarization. The tomato hybrids 'Alambra', Meloidogyne incognita resistant (gene Mi), and 'Duradoro' (susceptible), were planted after two months soil solarization. Weed seed bank and weed survival were evaluated by soil sampling and germination of viable seeds and by sampling the emerged plants 30 days after transplanting of the tomato seedlings. Soil samples were analyzed for their chemical properties after solarization and biofumigation. Soil solarization, chicken litter amendment and methyl bromide treatments reduced nematode populations and the number of egg masses on both tomato hybrids. However, 'Alambra' presented significantly higher total fresh and dry weight, plant height and fruit weight in comparison to 'Duradoro'. 'Alambra' was more responsive to treatments than 'Duradoro'. Methyl bromide fumigation and solarization reduced the number and survival of weed seeds in the soil. Solarization increased levels of $\mathrm{P}$ and $\mathrm{Cu}$, and reduced levels of $\mathrm{Zn}$ in the soil.
\end{abstract}

Keywords: Lycopersicon esculentum, Medoidogyne sp., soil disinfestation, physical control, weed, organic matter.

\section{(Recebido para publicação em 15 de janeiro de 2005; aceito em 17 de fevereiro de 2006)}

A solarização é um método de desinfestação que consiste na cobertura do solo úmido com polietileno transparente, na estação quente do ano, antes do plantio (Katan \& Devay, 1991). Essa cobertura provoca um efeito estufa que eleva a temperatura do solo causando a morte ou o enfraquecimento dos propágulos de microrganismos fitopatogênicos. Reduções de 42 a $100 \%$ na população de diversos gêneros de nematóides, incluindo Meloidogyne, Heterodera, Globodera, Pratylenchus, Ditylenchus, Paratrichodorus, Criconemella, Xiphinema, Helicotylenchus e Paratylenchus, foram observadas após a solarização do solo (Stapleton \& Devay, 1983, 1986). Além da ação direta do calor sobre os patógenos, os efeitos da solarização sobre a ocorrência de plantas daninhas e sobre as características químicas do solo podem influenciar positivamente o desenvolvimento das culturas e desfavorecer a sobrevivência de fitopatógenos no solo, atuando de maneira integrada no controle de doenças e plantas daninhas (Katan, 1981). Recentemente, a solarização vem sendo avaliada em conjunto com a biofumigação com o objetivo de aumentar a sua eficiência (Schoenmaker \& Ghini, 2001). A biofumigação consiste na incorporação de matéria orgânica ao solo, principalmente resíduos de brássicas ricos em enxofre e compostos ricos em nitrogênio, que durante a decomposição liberam substâncias tóxicas aos patógenos, reduzindo sua viabilidade no solo (Schoenmaker \& Ghini, 2001). Esta combinação tem potencial no aumento da eficácia dos tratamentos para o controle de patógenos e aumento da produtividade das culturas, principalmente quando a solarização isoladamente não proporciona um controle adequado dos patógenos alvo (Gamliel et al., 2000). A combinação da solarização com a incorporação de fontes de matéria orgânica ricas em nitrogênio ou em enxôfre, como cama de aves e resíduos de brássicas, tem apresentado bons resultados no controle de fitopatógenos do solo e estímulo sobre o crescimento e produção das plantas, mesmo na ausência de fitopatógenos, devido a mudanças nos componentes bióticos e 
abióticos do solo (Ghini et al., 2003). Embora vários trabalhos relatem mudanças na fertilidade dos solos submetidos à solarização (Katan, 1981; Grünzweig et al., 1999), poucos quantificaram estas alterações. Este trabalho teve como objetivo avaliar a eficiência da solarização, biofumigação e fumigação no controle de Meloidogyne $s p$. em cultivo protegido de tomate e seu efeito no crescimento e produtividade precoce das plantas, na fertilidade do solo e na sobrevivência de plantas daninhas.

\section{MATERIAL E MÉTODOS}

O experimento foi conduzido em casa de vegetação com cobertura plástica e telado lateral $(50 \times 8 \mathrm{~m})$ localizada na área experimental da Embrapa Hortaliças, Brasília (DF). O solo foi preparado e irrigado até a capacidade de campo e, no dia seguinte, as parcelas a serem solarizadas foram cobertas com plástico de polietileno (PE) de $50 \mathrm{~mm}$ de espessura (parcelas de $9 \mathrm{~m}^{2}$ ). Todo telado da casa de vegetação foi recoberto externamente com plástico de polietileno transparente de $50 \mathrm{~mm}$ de espessura, para garantir maiores temperaturas no interior da casa de vegetação. Os tratamentos incluíram a adição ao solo de cama de aves na proporção de 2\% (v:v), resíduos de couve-flor e de brócolos $(2 \% \mathrm{v}: \mathrm{v})$, tratamento com brometo de metila $\left(40 \mathrm{~cm}^{3} / \mathrm{m}^{2}\right)$ e testemunha (sem adição de resíduos), todos solarizados ou não solarizados, em três repetições, no delineamento inteiramente casualizado. As temperaturas do solo foram monitoradas com termômetro a 5,10 e $20 \mathrm{~cm}$ de profundidade, duas vezes por semana às 15:00 h, durante todo o período da solarização, de 27/08 a 30/10/03. A sobrevivência de nematóides foi determinada pela coleta e identificação de nematóides em amostras de solo retiradas dos diversos tratamentos, a 20 e $40 \mathrm{~cm}$ de profundidade, segundo Flegg e Hooper (1970) e Jenkins (1964). As espécies de plantas daninhas presentes foram monitoradas por meio de: 1) quantificação do banco de sementes no solo, em amostras compostas de 10 subamostras (fatias no perfil de 0 a $20 \mathrm{~cm}$ do solo), em um total de 8 litros de terra peneirada e seca ao ar, por parcela, segundo a técnica de germinação das sementes em casa de vegetação, conforme descrição de Gross (1990) e Schreiber et al. (1989); 2) contagem das plantas emergidas e peso da matéria seca total das plantas daninhas, presentes em amostras de $0,2 \mathrm{~m}^{2}$ da área útil da parcela, aos 30 dias após o plantio do tomate. Os solos das parcelas solarizadas e não solarizadas foram amostrados na profundidade de $0-10 \mathrm{~cm}$ e de 10-20 cm e analisados quimicamente quanto a $\mathrm{pH}, \mathrm{P}, \mathrm{K}, \mathrm{Ca}, \mathrm{Mg}, \mathrm{Na}, \mathrm{S}, \mathrm{Al}$, $\mathrm{H}+\mathrm{Al}$, matéria orgânica, $\mathrm{Cu}, \mathrm{Fe}, \mathrm{Zn}, \mathrm{Mn}$ e B. Todas as amostras de solo foram coletadas após a retirada dos plásticos utilizados na solarização. Após a solarização a área foi utilizada para plantio dos híbridos de tomate Duradoro (híbrido F1 desenvolvido na Embrapa Hortaliças) e Alambra (híbrido F1 resistente a Meloidogyne incognita, resistência monogênica Mi, Clause Tezier do Brasil) em fileiras alternadas nas parcelas. As mudas foram produzidas em bandejas de isopor e transplantadas aos 21 dias após a semeadura. Após 70 dias do transplante, as plantas foram coletadas e os sistemas radiculares de três plantas de cada material, em cada parcela, foram avaliados quanto ao número de galhas de nematóides segundo método de Sasser \& Taylor (1978). A presença de nematóides nas raízes foi avaliada através do índice de massas de ovos considerando as notas de 1 a 5 sendo: 1) raízes sem massas de ovos; 2) 1 a 5 massas de ovos nas raízes; 3) 6 a 15 massas de ovos nas raízes; 4) 16 a 30 massas de ovos nas raízes; 5) mais de 30 massas de ovos. Durante a primeira colheita, 70 dias após o transplante, foi determinado o peso da matéria fresca e seca da parte aérea sem os frutos, altura das plantas e peso dos frutos, em uma planta do híbrido Alambra e Duradoro de cada parcela. Os dados foram analisados com o programa estatístico Sisvar 4.3 (UFLA, 2000).

\section{RESULTADOS E DISCUSSÃO}

As médias das temperaturas do ar máximas nos meses de setembro e outubro foram $29,7^{\circ} \mathrm{C}$ e $30,3^{\circ} \mathrm{C}$, respectivamente. As temperaturas médias alcançadas no solo solarizado durante este período foram $46,9^{\circ} \mathrm{C} ; 40,7^{\circ} \mathrm{C}$ e $36,0^{\circ} \mathrm{C}$ a 5,10 e $20 \mathrm{~cm}$ de profundidade, respectivamente. No solo não solarizado foram obtidas as temperaturas $41,7^{\circ} \mathrm{C} ; 34,8^{\circ} \mathrm{C}$ e $35,2^{\circ} \mathrm{C}$, respectivamente, nas mesmas profundidades. As diferenças de temperatura obtidas entre o solo solarizado e o não solarizado a 5 , 10 e $20 \mathrm{~cm}$ de profundidade foram $5,2^{\circ} \mathrm{C} ; 5,9^{\circ} \mathrm{C}$ e $0,8^{\circ} \mathrm{C}$, respectivamente. As temperaturas médias alcançadas no solo solarizado neste experimento estiveram próximas das médias citadas por Katan (1981), entre 45 e $55^{\circ} \mathrm{C}$ a $5 \mathrm{~cm}$ de profundidade e 39 e $45^{\circ} \mathrm{C}$ a $20 \mathrm{~cm}$ de profundidade.

A solarização influenciou mais acentuadamente a fertilidade do solo na camada superficial, de $0-10 \mathrm{~cm}$. A Tabela 1 mostra os efeitos significativos nos teores de fósforo $(\mathrm{P})$ em três tratamentos, e de cobre $(\mathrm{Cu})$ e zinco $(\mathrm{Zn})$ em quatro deles. Os teores de $\mathrm{P}$ e de $\mathrm{Cu}$ aumentaram, enquanto o de $\mathrm{Zn}$ diminuiu em resposta à solarização. Em condições de campo, Basavaraju e Nanjappa (2000), também observaram aumento nos teores de $\mathrm{P}$ em alfisols solarizados. $\mathrm{O}$ aumento nos teores de $\mathrm{P}$ disponíveis observados no presente trabalho, inclusive na testemunha, sugere que as elevadas temperaturas alcançadas durante a solarização de alguma forma induziram dessorção do fosfato retido na fração sólida do solo. Embora existam resultados contraditórios, Rajan et al. (1996) relataram aumento na dissolução do fosfato de rocha adicionado ao solo pela elevação da temperatura. Além disso, a elevação da temperatura durante a solarização favorece o aumento da população microbiana saprofítica, acentuando a produção de diversos ácidos orgânicos por esses organismos contribuindo, assim, para a disponibilização do P. Ácidos orgânicos como citrato, malato e oxalato podem ser fortemente adsorvidos ao solo competindo com os sítios de adsorção de $\mathrm{P}$, aumentando a disponibilidade desse nutriente para as plantas (Haynes, 1984).

Hue (1992) observou que a eficiência dos adubos fosfatados aumenta acentuadamente quando aplicados juntamente com ácidos orgânicos puros ou com materiais produtores de ácidos, como os adubos verdes, estercos ou lodo de esgoto incorporados ao solo. 
Tabela 1. Composição química da camada de 0 a $10 \mathrm{~cm}$ de profundidade do solo solarizado ou não, submetido a diferentes tratamentos. Brasília, Embrapa Hortaliças, 2004.

\begin{tabular}{|c|c|c|c|c|c|c|c|c|c|c|c|c|c|c|c|c|c|}
\hline \multirow{2}{*}{ Tratamento } & \multirow{2}{*}{ Sol. } & \multirow{2}{*}{$\begin{array}{c}\text { M.O. } \\
\text { mg kg-1 }^{-1}\end{array}$} & \multirow{2}{*}{ pH } & $\mathbf{P}$ & $\mathbf{K}$ & $\mathrm{Na}$ & $\mathbf{s}$ & $\mathrm{H}+\mathrm{Al}$ & $\mathrm{Ca}$ & $\mathrm{Mg}$ & СTC & \multirow{2}{*}{$\begin{array}{l}\mathbf{V} \\
\%\end{array}$} & \multirow{2}{*}{\multicolumn{5}{|c|}{$\frac{\mathrm{Ln}}{\mathrm{mg} \mathrm{dm}{ }^{-3}}$}} \\
\hline & & & & \multicolumn{4}{|c|}{$\mathrm{mg} \mathrm{dm}^{-3}$} & \multicolumn{4}{|c|}{ cmolc $\mathrm{dm}^{-3}$} & & & & & & \\
\hline \multirow[t]{2}{*}{ Testemunha } & Sol 11 & 38,07 & 5,55 & $20,50^{*}$ & 316,67 & 108,33 & 90,23 & 6,60 & 6,37 & 2,40 & 16,65 & 60,24 & 3,03 & 83,57 & 3,50 & 651,17 & 0,43 \\
\hline & NSol & 34,53 & 5,60 & 13,20 & 250,00 & 110,33 & 74,30 & 6,40 & 5,97 & 2,43 & 15,92 & 59,62 & 2,68 & 91,73 & $6,42^{*}$ & 572,83 & 0,38 \\
\hline \multirow[t]{2}{*}{ Couve-flor } & Sol & 39,00 & 5,75 & 19,50 & 386,67 & 116,67 & 45,67 & 6,30 & 6,27 & 2,27 & 16,33 & 61,39 & $2,92^{*}$ & 83,43 & 4,17 & 673,33 & 0,43 \\
\hline & NSol & 39,07 & 5,85 & 18,80 & 375,00 & 144,33 & $81,43^{*}$ & 5,53 & 6,48 & 2,32 & 16,07 & 65,55 & 2,43 & 90,77 & 6,58 & 640,00 & 0,40 \\
\hline \multirow[t]{2}{*}{ Brocoli } & Sol & 37,13 & 5,68 & $25,83^{*}$ & 380,00 & & 46 & 6,17 & 6,43 & 2,18 & 16,22 & 61,96 & $3,12^{*}$ & 80,90 & 3,85 & 5,17 & 0,42 \\
\hline & NSol & 35,47 & 5,82 & 12,30 & 383,33 & 123,00 & 63,27 & 5,63 & 6,55 & 2,20 & 15,90 & 64,62 & 2,38 & 81,77 & $7,68^{*}$ & 691,83 & 0,40 \\
\hline \multirow{2}{*}{$\begin{array}{l}\text { Cama de } \\
\text { aves }\end{array}$} & Sol & 39,00 & 5,63 & $71,50^{*}$ & 456,67 & 111,33 & 50,10 & 6,20 & 6,68 & 2,35 & 16,89 & 63,28 & $3,05^{*}$ & 74,67 & 3,12 & 633,83 & 0,37 \\
\hline & NSol & 37,23 & 5,78 & 52,00 & 470,00 & 161,67 & 64,40 & 5,97 & 6,47 & 2,53 & 16,87 & 64,50 & 2,28 & 87,90 & $10,00^{*}$ & 725,83 & 0,50 \\
\hline \multirow{2}{*}{$\begin{array}{l}\text { Brometo } \\
\text { metila }\end{array}$} & Sol & 36,30 & 5,78 & 26,20 & 313,33 & 94,00 & 57,23 & 6,17 & 5,93 & 2,25 & 15,56 & 60,45 & $3,47^{*}$ & 75,37 & 2,53 & 581,17 & 0,37 \\
\hline & NSol & 37,23 & 5,70 & 23,70 & 316,67 & 108,33 & 81,43 & 6,20 & 6,50 & 2,35 & 16,33 & 61,97 & 2,85 & 84,00 & $7,97^{*}$ & 633,17 & 0,43 \\
\hline CV (\%) & & 5,52 & 2,2 & 10,81 & 18,73 & 15,14 & 31,31 & 10,73 & 9,73 & 11,78 & 5,22 & 6,76 & 9,84 & 23,39 & 27,94 & 9,42 & 12,3 \\
\hline
\end{tabular}

*Médias significativamente diferentes entre solos solarizados e não solarizados, dentro de cada tratamento, pelo teste de Tukey a $5 \%$ de probabilidade. ${ }^{1 /}$ Sol = solarizado; NSol= não solarizado.

Independentemente da solarização, o solo que recebeu cama de aves apresentou os maiores teores de P na camada superficial (Tabela 1). A cama de aves utilizada no presente trabalho apresenta $2,0 \%$ de $\mathrm{P}$ total e relação $\mathrm{C}: \mathrm{P}$ (carbono:fósforo) em torno de 20, favorecendo portanto a mineralização da matéria orgânica original do solo e da adicionada. Entretanto, o teor de matéria orgânica não diferiu entre os tratamentos solarizados e não solarizados (Tabela 1), resultado também observado por Ghini et al. (2003). Embora tenha havido liberação de P orgânico com a solarização, provavelmente as quantidades liberadas são muito pequenas em relação ao estoque de $\mathrm{P}$ da matéria orgânica, não se refletindo rapidamente no teor de matéria orgânica do solo neste curto intervalo de tempo (64 dias).

A disponibilidade de $\mathrm{Zn}$ diminuiu e a de $\mathrm{Cu}$ aumentou em quase todos os tratamentos solarizados (Tabela 1). Ghini et al. (2003) também observaram redução nos teores dos micronutrientes $\mathrm{Zn}, \mathrm{Cu}$ e $\mathrm{Fe}$ em solos submetidos à solarização, enquanto Grünzweig et al. (1999) verificaram aumentos nos teores destes nutrientes em solos solarizados. A liberação de nutrientes no solo pode estar relacionada à ação da solarização sobre a microbiota do solo. Parte importante dos nutrientes presentes na matéria orgânica do solo está imobilizada na microbiota e se torna disponível com sua morte e decomposição. Segundo Siqueira \& Franco (1988), os nutrientes

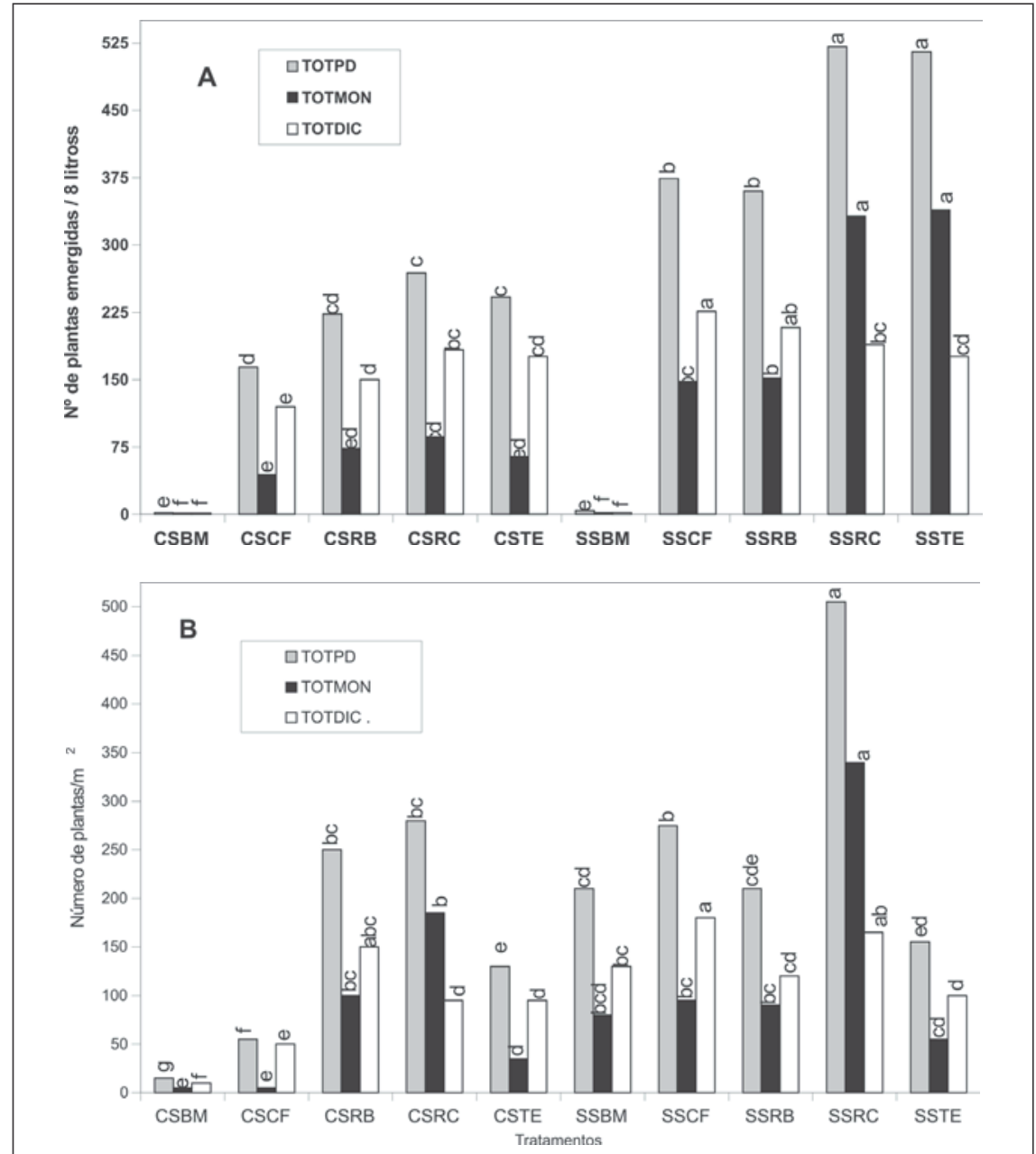

Figura 1. Soma de três fluxos de germinação das sementes em amostras de 8 litros de solo sob a influência de solarização, fumigação e suplementos orgânicos no cultivo de tomate, em ambiente protegido (A); Classes de plantas daninhas emergidas $/ \mathrm{m}^{2}(\mathbf{B})$. Legendas: $\mathrm{CS}=$ com solarização, $\mathrm{SS}=$ sem solarização, $\mathrm{BM}=$ brometo de metila, $\mathrm{CF}=$ cama de aves, $\mathrm{RB}=$ resíduos de brócolos, $\mathrm{RC}=$ resíduos de couve-flor, $\mathrm{TE}=$ testemunha; $\mathrm{TOTPD}=$ total de plantas daninhas, TOTMON $=$ total de monocotiledôneas, TOTDIC $=$ total de dicotiledôneas. Os tratamentos seguidos das mesmas letras em cada gráfico não diferem entre si pelo teste $\mathrm{T}$ (DMS), ao nível de 5\% de probabilidade. Brasília, Embrapa Hortaliças, 2004. 


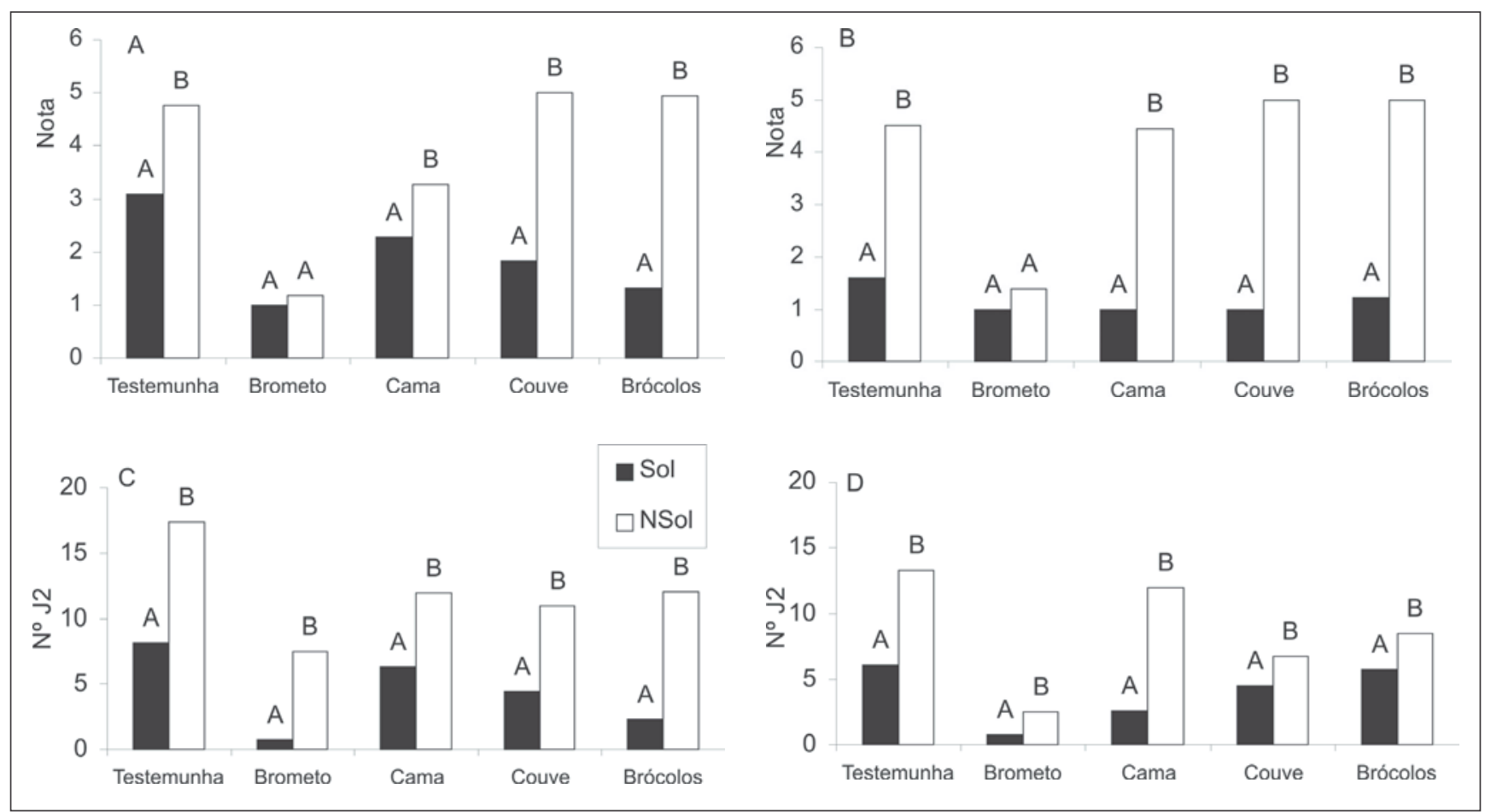

Figura 2. Índices de massas de ovos de Meloidogyne $s p$. nas raízes: híbrido Duradoro (A); híbrido Alambra (B); e $\mathrm{n}^{\circ}$ de larvas J2 de Meloidogyne sp. no solo 0-20 cm de profundidade (C) e 20-40 cm (D). Tratamentos:Testemunha, Cama de aves, couve-flor, brócolos e brometo de metila. Sol = solarizado, Nsol= não solarizado. Tratamentos seguidos da mesma letra, em cada gráfico, não diferem entre si pelo teste de Tukey ao nível de 5\% de probabilidade. Brasília, Embrapa Hortaliças, 2004.

armazenados na biomassa microbiana atingem valores bastante elevados, alcançando $100 \mathrm{~kg}$ de N, $80 \mathrm{Kg}$ de P, $70 \mathrm{~kg}$ de $\mathrm{K}$ e $11 \mathrm{~kg}$ de Ca por ha. A biomassa é reciclada cerca de 10 vezes mais rapidamente em comparação com a matéria orgânica morta do solo e grande parte dos nutrientes é liberada durante a reciclagem. Ghini et al. (2003) verificaram a redução da atividade microbiana, avaliada pela hidrólise de diacetato de fluoresceína após a solarização do solo. Estudos mais detalhados relacionando a liberação de nutrientes no solo e os efeitos da solarização na biomassa microbiana são necessários.

Os resultados aqui apresentados evidenciam o efeito favorável da solarização na disponibilidade de nutrientes do solo. Em condições tropicais, o fósforo é o nutriente mais limitante à produtividade das culturas. Assim, essa maior disponibilidade de nutrientes, especialmente de fósforo, significará maior qualidade e produtividade dos cultivos com economia de fertilizantes.

Os tratamentos que apresentaram menores bancos de sementes viáveis no solo foram os tratados com brometo de metila, com ou sem solarização, dife- rindo dos demais (Figura 1A). O número total de plantas daninhas da testemunha solarizada diferiu significativamente da testemunha não solarizada, indicando também o efeito da solarização, embora em menor intensidade do que a fumigação. Os tratamentos cama de aves e resíduos de brócolos, em solo solarizado ou não solarizado, reduziram significativamente o número total de sementes viáveis de plantas daninhas no solo, em relação aos tratamentos testemunha e resíduo de couve-flor em solo não solarizado (Figura 1A). Em relação ao total das plantas daninhas emergidas no solo e presentes aos 30 dias após o transplante do tomateiro, sob cultivo protegido, os tratamentos com brometo de metila e cama de aves, ambos em solo solarizado, diferiram dos demais com ou sem solarização (Figura 1B). Conclui-se que a fumigação e a solarização reduziram a viabilidade das sementes no solo e a sobrevivência das plantas daninhas, havendo maior ação do tratamento químico que do físico.

Houve diferença significativa no índice de massas de ovos de nematóides Meloidogyne sp. nas raízes das plantas cres- cidas no solo solarizado e não solarizado nos dois híbridos testados, Alambra e Duradoro (Figura 2AeB). O efeito da temperatura é considerado o fator nematicida primário resultante da solarização. Vários trabalhos foram realizados para tentar determinar o ponto de morte pelo calor e estabelecer as relações tempo/temperatura letais para os nematóides. No entanto, outras alterações físicas, químicas e biológicas que ocorrem durante o processo de solarização são fatores importantes (Stapleton \& Devay, 1986).

A solarização e o uso do brometo de metila reduziram a presença de nematóides nas raízes. O número de juvenis (J2) recuperados do solo nos diversos tratamentos foi reduzido significativamente pela solarização nas amostras de solo coletadas nas profundidades de 0-20 cm e de 20-40 cm (Figura 2 C e D). Observou-se, desta forma, além da diminuição da formação de galhas radiculares em tomate, uma redução significativa na liberação de nematóides nos solos solarizados (Figura 2).

Overman (1981) testou a solarização do solo no controle de Meloidogyne incognita em tomate. Neste trabalho não 
foi verificado efeito da solarização no número de galhas nas plantas, mas a solarização foi feita por apenas 30 dias em solo fortemente infestado. Stapleton \& Devay (1983), no entanto, verificaram redução na densidade de Meloidogyne, Heterodera, Pratylenchus, Paratrichodorus, Criconemella, Xiphinema e Paratylenchus spp. no solo após seis semanas de solarização. A solarização por 139 dias resultou em redução significativa do número de galhas causadas por Meloidogyne javanica em quiabeiro em experimento realizado por Bettiol et al. (1996). Aparentemente, o tempo de solarização do solo, assim como as temperaturas alcançadas e o nível de infestação do solo, são fatores importantes para que se obtenha o controle. Neste trabalho, verificou-se que o número de galhas de nematóides formadas em tomateiro crescido no solo solarizado foi significativamente menor que no solo não solarizado. A fumigação com brometo de metila reduziu o número de galhas independentemente da solarização do solo, mas a adição de matéria orgânica, cama de aves ou resíduos de brássicas não apresentou efeitos significativos. Stapleton \& Duncan (1998) avaliaram a adição de resíduos de brássicas sobre a sobrevivência de nematóides e fungos fitopatogênicos no solo. Foi verificado que a adição dos resíduos de brássicas reduziu o número de galhas em tomateiro em 95-100\%, quando o solo foi aquecido a $38^{\circ} \mathrm{C}$, após 7 dias de incubação. Este experimento, no entanto, foi feito em vasos em casa de vegetação, e não diretamente no solo. Os mesmos efeitos não foram observados no presente trabalho, embora tenha sido possível notar uma tendência de maior redução do número de galhas nos tratamentos com solarização e resíduos orgânicos quando comparados com a solarização isoladamente. O estudo do efeito da adição de diferentes quantidades e tipos de matéria orgânica pode fornecer resultados positivos para o controle de nematóides. Diferenças nas concentrações de compostos voláteis presentes no solo após a adição de resíduos de brássicas e aquecimento foram detectadas por Gamliel \& Stapleton (1993), que verificaram a geração de uma gama de compostos incluindo alcoois, aldeídos, sulfetos e isoticianatos. A concentração de sulfetos

Tabela 2. Altura, massa da matéria fresca e seca da parte aérea e produção de frutos na primeira colheita (70 dias após o transplante) dos híbridos de tomate Alambra e Duradoro em solos solarizados e não solarizados em casa de vegetação Brasília, Embrapa Hortaliças, 2004.

\begin{tabular}{lccccc}
\hline \multirow{2}{*}{ Variáveis } & \multicolumn{2}{c}{ Alambra } & & \multicolumn{2}{c}{ Duradoro } \\
\cline { 2 - 3 } \cline { 5 - 6 } & Solarizado & Não Solarizado & & Solarizado & Não solarizado \\
\hline Altura (m/planta) & $1,989 a$ & $1,418 \mathrm{~b}$ & & $1,699 \mathrm{a}$ & $1,383 \mathrm{~b}$ \\
Matéria fresca (kg/planta) & $1,45 \mathrm{a}$ & $1,11 \mathrm{~b}$ & & $1,28 \mathrm{a}$ & $1,11 \mathrm{a}$ \\
Matéria seca (g/planta) & $211,78 \mathrm{a}$ & $183,9 \mathrm{~b}$ & & $218,81 \mathrm{a}$ & $180,38 \mathrm{a}$ \\
Peso frutos (kg/planta) & $2,62 \mathrm{a}$ & $1,44 \mathrm{~b}$ & & $1,56 \mathrm{a}$ & $1,18 \mathrm{a}$ \\
\hline
\end{tabular}

Valores seguidos pela mesma letra, em cada linha, para o híbrido Alambra ou Duradoro, não diferem entre si pelo teste de Tukey a $5 \%$ de probabilidade.

e isoticianatos correlacionou-se inversamente com a sobrevivência de Pythium ultimum e Sclerotium rolfsii no solo, reduzindo o número de propágulos viáveis destes organismos. Os tratamentos solarizados apresentaram também número significativamente menor de larvas de Meloidogyne sp. e, neste caso, o efeito do brometo de metila só foi verificado quando em conjunto com a solarização do solo.

A avaliação do desenvolvimento das plantas e da produção precoce indicaram maior altura, massa da matéria fresca e seca da parte aérea e peso de frutos nas plantas do híbrido Alambra crescidas no solo solarizado (Tabela 2). As plantas do híbrido Duradoro, no entanto, não apresentaram diferenças significativas, exceto para a altura das plantas, com maior comprimento nos solos solarizados.

O tomate Alambra respondeu melhor ao processo de solarização do solo, indicando a efetividade da utilização de duas estratégias para manejo da doença (o uso de variedades resistentes e a solarização) como método eficiente de controle. Neste experimento, fatores relacionados a características do híbrido Alambra permitiram melhor resposta quando a população de nematóides no solo foi reduzida pela solarização. O uso em conjunto da solarização e de variedades que apresentem resistência a nematóides deve ser melhor avaliado e pode ser uma solução viável e bastante interessante para o controle de nematóides na produção de tomate.

\section{LITERATURA CITADA}

BASAVARAJU HK; NANJAPPAHV. 2000. Nutrient release due to soil solarization in alfisols. Indian Journal of Agricultural Research, 34: 217-222.
BETTIOL W; GHINI R; CUNHA MIB; TRATCH R; GALVÃO JAH. 1996. Solarização do solo para o controle do nematóide das galhas em quiabeiro. Horticultura Brasileira, 14: 158-160.

FLEGG JJM; HOOPER DJ. 1970. Extraction of free-living stages from soil. In: SOUTHEY JF. (Ed.). Laboratory Methods for Work with Plant and Soil Nematodes. London: Ministry of Agriculture, Fisheries and Food, p. 5-30.

GAMLIEL A; AUSTERWEIL M; KRITZMAN G. 2000. Non-chemical approach to soilborne pest management - organic amendments. Crop Protection, 19: 847-853.

GAMLIEL A; STAPLETON JJ. 1993. Characterization of antifungal volatile compounds evolved from solarized soil amended with cabbage residues. Phytopathology, 83: 899-905.

GHINI R; PATRICIO FRA; SOUZA MD; SINIGAGLIA C; BARROS BC; LOPES MEBM; TESSARIOLI NETO J; CANTARELLA H. 2003. Efeito da solarização sobre as propriedades físicas, químicas e biológicas de solos. Revista Brasileira de Ciência do Solo, 27: 71-79.

GROSS KL. 1990. A comparison of methods for estimating seed numbers in the soil. Jounal of Ecology, 78: 1079-1093.

GRÜNZWEIG JM; KATAN J; BEN-TAL Y; RABINOWITCH HD. 1999. The role of mineral nutrients in the increased growth response of tomato plants in solarized soil. Plant and Soil, 206: 21-27.

HAYNES RJ. 1984. Lime and phosphate in the soil-plant system. Advances in Agronomy, 37: 249315 .

HUE NV. 1992. Correcting soil acidity of a highly weathered ultisol with chicken manure and sewage sludge. Comm. Soil Science Plant Anal., 23: 241-264. JENKINS WR. 1964. A rapid centrifugal flotation technique for separating nematodes from soil. Plant Disease Report, 48: 692.

KATAN J. 1981. Solar heating (solarization) of soil for control of soilborne pests. Annual Review of Phytopathology, 19: 211-236.

KATAN J; DEVAY JE. 1991. Soil solarization: Historical perspectives, principles and uses. In: KATAN J; DeVAY JE. (Ed.). Soil solarization. Boca Raton: CRC Press, 2: 23-38.

OVERMAN AJ. 1981. Off-season land management and soil fumigation for tomato on sandy soil. Journal of Nematology, 13: 455.

RAJAN SSS; WATKINSON JH; SINCLAIR AG. 1996. Phosphate rocks for direct application to soils. Advances in Agronomy, 57: 77-159. 
SASSER JN; TAYLOR AL. 1978. Biology, identification and control of root-knot nematodes (Meloidogyne species). Raleigh: North Carolina State University, 111p.

SCHOENMAKER IAS; GHINI R. 2001 Biofumigação do solo para o controle de Pythium spp. Summa Phytopathologica, 27: 308-312.

SCHREIBER RL; LECK MA; PARKER VT. 1989. Seed banks: general concepts and methodological issues. In: LECK MA; PARKER VT; SIMPSON RL. (Ed.). Ecology of soil seed banks. London: Academic Press, p. 3-8.
SIQUEIRA JO; FRANCO AA. 1988. Biotecnologia do solo - Fundamentos e perspectivas. Brasília: MEC-ESAL-FAEPE-ABEAS, $236 \mathrm{p}$. STAPLETON JJ. 2000. Soil solarization in various agricultural production systems. Crop Protection, 19: 837-841.

STAPLETON JJ; DEVAY JE. 1983. Response of phytoparasitic and free-living nematodes to soil solarization and 1,3-Dichloropropene in California. Phytopathology, 73: 1429-1436.
STAPLETON JJ; DEVAY JE. 1986. Soil solarization: a non-chemical approach for management of plant pathogens and pests. Crop Protection, 5: 190-198.

STAPLETON JJ; DUNCAN RA. 1998. Soil desinfestation with cruciferous amendments and sublethal heating: effects on Meloidogyne incognita, Sclerotium rolfsii and Pythium ultimum. Plant Pathology, 47: 737-742. 